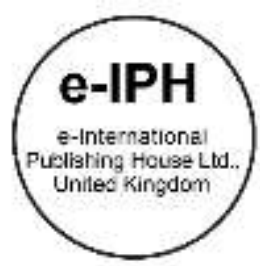

\title{
Visualization Process of Temporary Converted Facilities to Accommodate Quarantine and Treatment Centre (PKRC) Layouts in Malaysia Agriculture Expo Park Serdang (MAEPS)
}

\author{
Siti Aisyah Muhammad ${ }^{1}$, Nik Nurul Hana Hanafi ${ }^{1}$, Tengku Fauzan Tengku Anuar ${ }^{2}$, Zhang Hequan ${ }^{3}$ \\ 1 Faculty of Architecture and Ekistics (FSE), Universiti Malaysia Kelantan, Malaysia \\ 2 Faculty of Creative Technology and Heritage (FTKW), Universiti Malaysia Kelantan, Malaysia \\ 3 University of Zhejiang, Hangzhou 310018, China
}

aisyah@umk.edu.my1, hana.h@umk.edu.my²

tengkufauzan@umk.edu.my3 ${ }^{3}, 20170011 @ c u z . e d u . c n^{4}$

Tel: +60193833608

\begin{abstract}
This study aims to develop a reference platform for converting Malaysia Agriculture Expo Park Serdang (MAEPS) to the Low-Risk COVID-19 Quarantine and Treatment Centre (PKRC) to face the increased numbers Covid-19. This study employed qualitative methodologies and further developed 3D modeling involving AutoCAD, SketchUp, and V-Ray software. The limitation is developing a 3D model visualization of MAEPS on Phase 1 and Phase 2 at Hall $A$ only. The findings display the application of $3 \mathrm{D}$ visualization potentially becomes a reference to creating the quarantine centre in the future.
\end{abstract}

Keywords: Covid-19; pandemic; quarantine centre; 3D visualization

eISSN: 2398-4287@ 2021. The Authors. Published for AMER ABRA cE-Bs by e-International Publishing House, Ltd., UK. This is an open access article under the CC BYNCND license (http://creativecommons. org/licenses/by-nc-nd/4.0/). Peer-review under responsibility of AMER (Association of Malaysian Environment-Behaviour Researchers), ABRA (Association of Behavioural Researchers on Asians/Africans/Arabians) and CE-Bs (Centre for Environment-Behaviour Studies), Faculty of Architecture, Planning \& Surveying, Universiti Teknologi MARA, Malaysia.

DOI: https://doi.org/10.21834/ebpj.v6i18.3055

\subsection{Introduction}

The Covid-19 pandemic has been with us for over two years, leading to the establishment of hundreds of Low-Risk COVID-19 Quarantine and Treatment Centres (PKRC) in every state to meet the growing demand of Covid-19 positive patients. The PKRC formally opened on April 16, 2020, with the first patient admitted on April 21, 2020. It was legally closed on July 15, 2020, and daily cases dropped; nevertheless, on December 9, 2020, Malaysia Agriculture Expo Park Serdang (MAEPS) PKRC was forced to reopen with a thorough redesign of the space layout. During the initial phase of the PKRC, 1362 patients were hospitalised, with 94 percent being males and 69 percent being illegal aliens. To accommodate the growing number of patients, the PKRC Phase 2 reopened with an enormous capacity of 10000 beds. The remodeling intends to convert the conference hall into a PKRC with updated amenities and services comparable to the hospitals. The facilities include clinical services, wards for COVID-19 patients, a pharmacy, an X-ray room, resuscitation rooms to stabilize patients in emergencies, and pathology laboratory services (interview with Encik Zaidi b Shahrim, Chief Executive Officer of Mardi Corporation, 2020 The second phase received fewer Category 1 and Category 2 patients and treated Covid-19 patients in Category 3 who have symptomatic Pneumonia and Category 4 who have symptomatic Pneumonia and require supplementary oxygen (Ministry of Health Malaysia, 2020). As a result of the varying space requirements, the MAEPS PKRC Phase 1 and Phase 2 layouts were changed. The

eISSN: 2398-4287@ 2021. The Authors. Published for AMER ABRA cE-Bs by e-International Publishing House, Ltd., UK. This is an open access article under the CC BYNCND license (http://creativecommons.org/licenses/by-nc-nd/4.0/). Peer-review under responsibility of AMER (Association of Malaysian Environment-Behaviour Researchers), ABRA (Association of Behavioural Researchers on Asians/Africans/Arabians) and cE-Bs (Centre for Environment-Behaviour Studies), Faculty of Architecture, Planning \& Surveying, Universiti Teknologi MARA, Malaysia.

DOI: https://doi.org/10.21834/ebpj.v6i18.3055 
layout adjustment is partly due to a better understanding of the virus and the best potential for viral propagation via quarantine procedures. According to the guidelines, the PKRC is also forbidden from being visited by any tourist or member of the general public (Muhammad et al., 2021). As a result, 3D visualisation can aid the quarantine center's overview. With the possible reference of MAEPS 3D visualisation, the challenges of the optimal spatial arrangement of quarantine centres around the country may be resolved. The objective of this study is to develop the 3D visualization of the MAEPS PKRC of both Phase 1 and Phase 2, specifically Hall A. This study aims to create a platform of reference about a suitable layout for the quarantine centre of the pandemic in the future.

\subsection{Literature Review}

\subsection{Low-Risk Covid-19 Quarantine and Treatment Centre (PKRC)}

Several instructions were supplied by the Ministry of Health (MOH) and the National Disaster Management Agency (NADMA) to develop and operate the quarantine centre. Due to the severe flood in 2014, NADMA was forced to take immediate emergency measures (Hanafi et al., 2021). As a backdrop, the MAEPS facilities were the first in Malaysia to include quarantine and a Low-Risk COVID-19 Treatment Centre, with two main halls totaling $14200 \mathrm{~m} 2$ and 604 beds for Persons Under Surveillance (PUS). The shift led by NADMA to the Work Department (JKR), headed by Arkitek Hasnah Yun, had to contend with the issue of meeting criteria for the spatial organisation and people mobility to manage the infectious illness. The design must also meet the Fire Fighter Department's active and passive fire prevention regulations that include a provision for pathways and an emergency assembly point, the location of fire extinguishers, and appropriate signages. Unlike the NADMA's previous work for the post-disaster of flood in 2014, where the design of the house was to adapt the residents' social activities (Hanafi et al., 2021).

MOH also issued the Quarantine Station Guideline (Guidelines COVID-19 Management No.5/2020, amended on March 24, 2020), which states that the installation of a quarantine station is required by Section 14 of the Prevention and Control of Infectious Disease Act 1988 (Act 342). (MOH, 2020). "The quarantine station is to be utilised for isolation or surveillance of any person who is infected or whom the Authorized Officer has cause to think is infected to be taken to a quarantine station until the individual may be discharged without posing any threat to the public," according to the Act (2020). This requires the collaboration of several authorities, including the District Health Office, the District Welfare Department, the Malaysian Royal Police, the Army, the Local Council, the PGA, and others. MAEPS, as a PKRC at the national level, thereby followed the standards outlined in Annex 32 Quarantine centre (MOH, 2020). According to Zaidi (2020), the management in this PKRC of MAEPS was tight, with 100 percent compliance among local enterprises to the Annex 32 rules. In terms of specifics, the purpose of building a quarantine centre was to isolate diseased and potentially contaminated individuals from healthy individuals. Furthermore, it is intended to restrict the mobility of people affected to prevent the disease from spreading. MAEPS also met the following requirements for a quarantine gazette centre:

i. Space layout:

If shared space is required, the distance between beds must be at least 1 metre. This cohort approach is only applicable in favourable scenarios (MOH, 2020). MAEPS also met additional requirements, such as having a space for PPE and clinical exams. The beds were donated by a local manufacturer, which constructed and painted them at MAEPS within four days of the PKRC's establishment. They had to verify that the beds met $\mathrm{MOH}$ standards, with no edgy surfaces or fabric used for the mattress and pillow coverings. The MAEPS convention hall already featured toilets in terms of amenities and facilities, some of which had to be refurbished to become restrooms with safety and health criteria.

ii. Security and safety:

Furthermore, MAEPS was supervised by the National Security Council to verify that those quarantine requirements were satisfied. Polis Diraja Malaysia (PDRM), the Army, and RELA were in charge of safety. Two sharpshooters or snipers were stationed in the tower near Hall A, MAEPS, to patrol the perimeter of the facilities, which were also surrounded by barbed wire fences. Furthermore, Angkatan Tentera Malaysia (ATM) and PDRM focused and aided with security and safety factors such as spatial organisation concentrating on openings and the building perimeter, including essential coordination and tagging. The material used for the PKRC has to meet health and safety standards.

\section{iii. Cleanliness}

There were two sorts of cleanliness required: clinical waste, which was the responsibility of the District Health Office, and general cleanliness and general garbage, which was the responsibility of the Local Council.

iv. Food:

The food supply had to pass three nutrition and probable toxicity tests before it was provided to patients and frontline workers under the supervision of the District Health Office. The food supply was the responsibility of the District Welfare Department.

v. Staff duty:

The Incidence Commander coordinated the staff on duty throughout the MAEPS as it became a PKRC.

vi. Linen:

The concession extended from the hospital services managed the linen and clinical waste at MAEPS.

vii. Water supply: 
The Work Department was responsible for supplying water to the quarantine centre.

The conversion of the hall must also meet the standards of UBBL 133 Final Exit, UBBL 166 Alternative exits, UBBL 171 Horizontal exit, and UBBL 133, UBBL 169 Exit route. The travel distance in the authorised region should be attainable, as specified in UBBL 165. The width of the apertures to Hall A and Hall C met all of the stipulated emergency exits and travel distance criteria, albeit with tight security reinforcements. MAEPS also had to meet with the Fire Fighter Department's requirements for fire apparatus such as fire vehicles, pumping equipment for extended ladders, turntables, and hydraulic platforms. CCTV, a public address system, and a wireless intercom were also used to supplement the security system. Telecom Malaysia (TM) supplied a free high-speed Wi-Fi connection to the MAEPS as a PKRC to help with the health recording and registration system at this PKRC (Rafidah, 2020). Thus, the idea for current research derived from the conversion of MAEPS to become the PKRC with two phases of different space layout to overview the differences as the PKRC as the future reference.

\subsection{D Visualization in Spatial Planning}

Digital documentation has grown in popularity among academics and practitioners during the last two decades. Despite the extensive range of uses and customization capabilities, it is partly owing to its adaptability at many stages of the preservation and documenting of the process. For example, digital archiving in historical preservation plays a vital role in conserving records and recovering data from buildings. This covers 3D models as well as associated semantics. However, 3D visualization, particularly in spatial design, has become a trend, increasing and utilizing 3D digitalization and visualisation in architecture. According to Centofanti and Brusaporci (2013), the usefulness of a 3D model application for a restoration architecture project, for example, faces a number of problems, including the validation and dissemination of agreed-upon standards for 3D configuration. There is no particular programme required to create the $3 \mathrm{D}$ visualisation and simulation, but the impact must convey the information required for future reference. When focusing on the structure of the quarantine centre, the appropriate individuals must consider disease preventive action and meet behavioural demands at the same time. As a consequence, 3D visualisation may be used to simulate the actual architecture of the specialised PKRC in order to determine the ideal arrangement of regions to assist officers and patients. The creation of the PKRC's 3D visualisation brings a new way to layout design choices and enables optimal space planning and management in healthcare. According to De Oliveira (2000), "simulation is a valuable tool for easing the development of new medical facilities since it gives a method to reflect on critical concerns linked with the planning." The case study at Hospital Cardoso Fontes in Rio de Janeiro, Brazil, demonstrated the use of 3D visual simulation in assessing the functioning and space arrangement of the hospital using 3D Max software and 3D Fashion simulation. Figure 1 is a simulation of 3D visualisation of a new medical facility suggested by De Oliveira (2004).

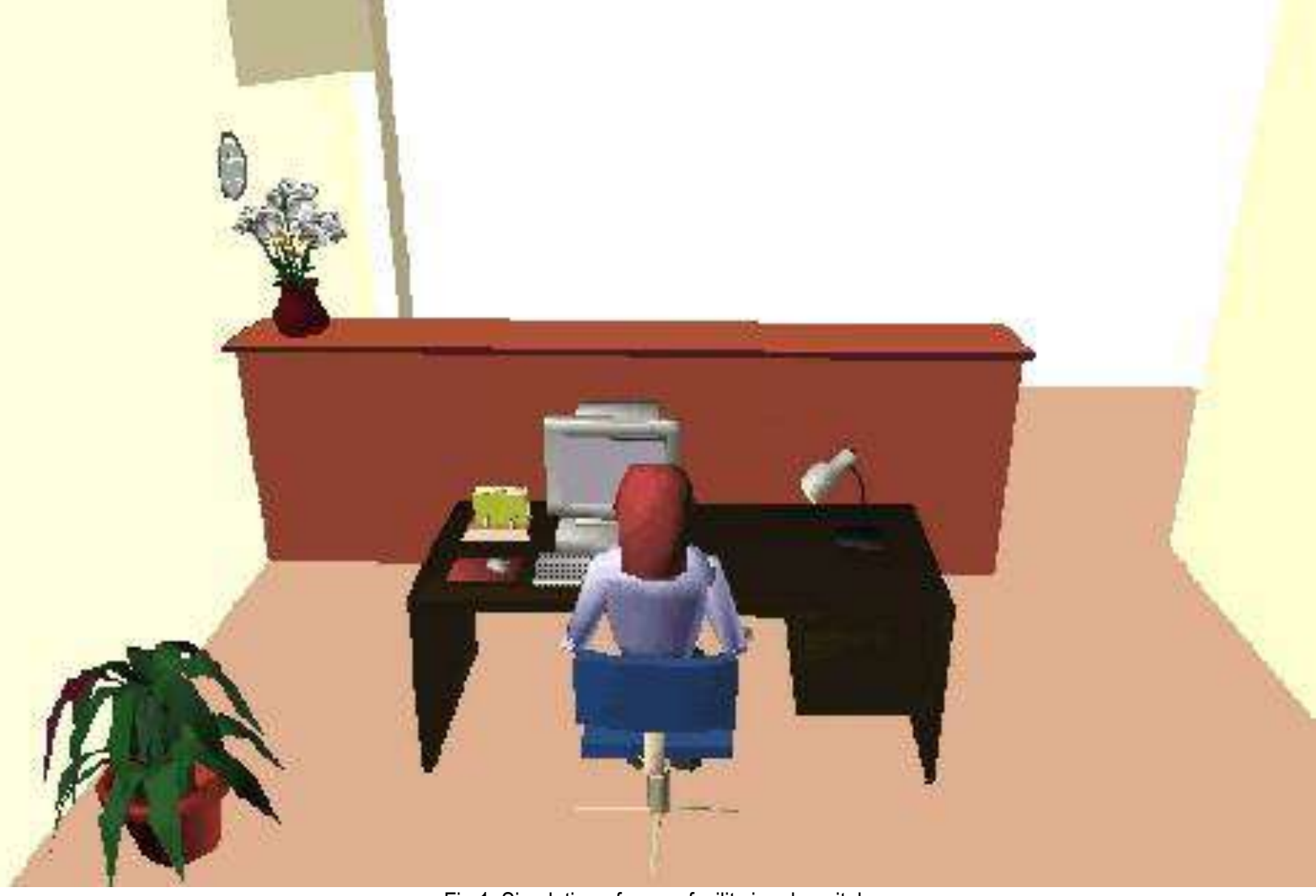

Fig.1: Simulation of a new facility in a hospital

(Source: De Oliveira,2004) 


\subsection{Methodology}

A focus group interview was done with Mardi Corp's Chief Executive Officer and personnel. The goal is to ascertain the specific operational activities performed throughout the changeover by the Mardi Corporation, which was in charge of the venue owner and amenities. The exchange of experiences shed light on the administration and monitoring of all teams and the necessary spaces. The data was evaluated, and the findings were used to understand the variables underlying the successful transition of MAEPS into Malaysia's first big interim quarantine centre in a short period of time. Using AutoCAD, Sketch-Up, and V-Ray 3D Render, the data was then transformed into 3D modelling animation. The $3 \mathrm{~d}$ visualizations of both phases indicated the different layout for Person Under Surveillance (PUS), where the application of the $3 \mathrm{D}$ visualizations can be a model of reference for academic and emergency situations in the future where the respective persons involved might find the improvement to develop the quarantine centre in the future. The 3D visualization will be uploaded on the online platform and can be shared with the public.

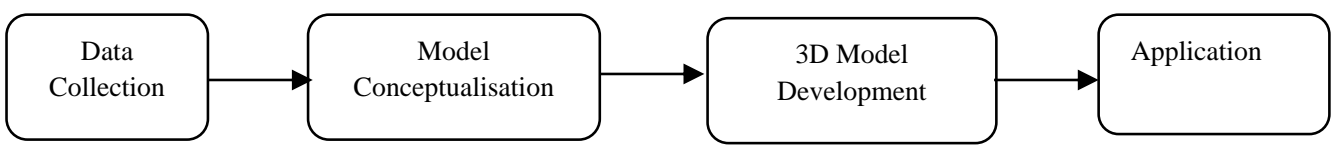

Fig.2: The 4-stages methodology applied to develop 3D visualization of the quarantine centre

\subsection{Findings}

In developing the 3D modelling layout, important facts regarding MAEPS and PKRC were examined based on the interview and the literature. Because the hall was column-free, multiple compartments could be given to it throughout the remodeling. NADMA and its agencies had few difficulties in coordinating spatial zoning and circulation. Figure 3 depicts the plan arrangement of Hall A, MAEPS, following the conversion to PKRC. Hall $A$ is an utterly air-conditioned room with a height clearance of up to 9 metres and three sections wings that have been turned into a gym and a PUS rest area. The actions within Hall A were closely monitored by those on the front lines, with particular attention paid to the prevention of potentially contagious illnesses. The circulation and spatial organization of the Red Zone allocated for the Person Under Surveillance (PUS) complied with infection protection standards by ensuring the correct distance and height of all compartments. COVID-19 is spread by water droplets and is not an airborne spreader at Phase 1 of PKRC. Hall C was dedicated to those on the frontline. It comprised a meeting area, resting area, lounge, counseling area, and more as most staff could not return home. Figure 4 shows the transformation work of the main hall to be the first Low-Risk Covid-19 Quarantine and Treatment Centre (PKRC) in Malaysia.

\section{COVID-19 ADDITIONAL HOSPITAL}

HALL A, MAEPS, SERDANG

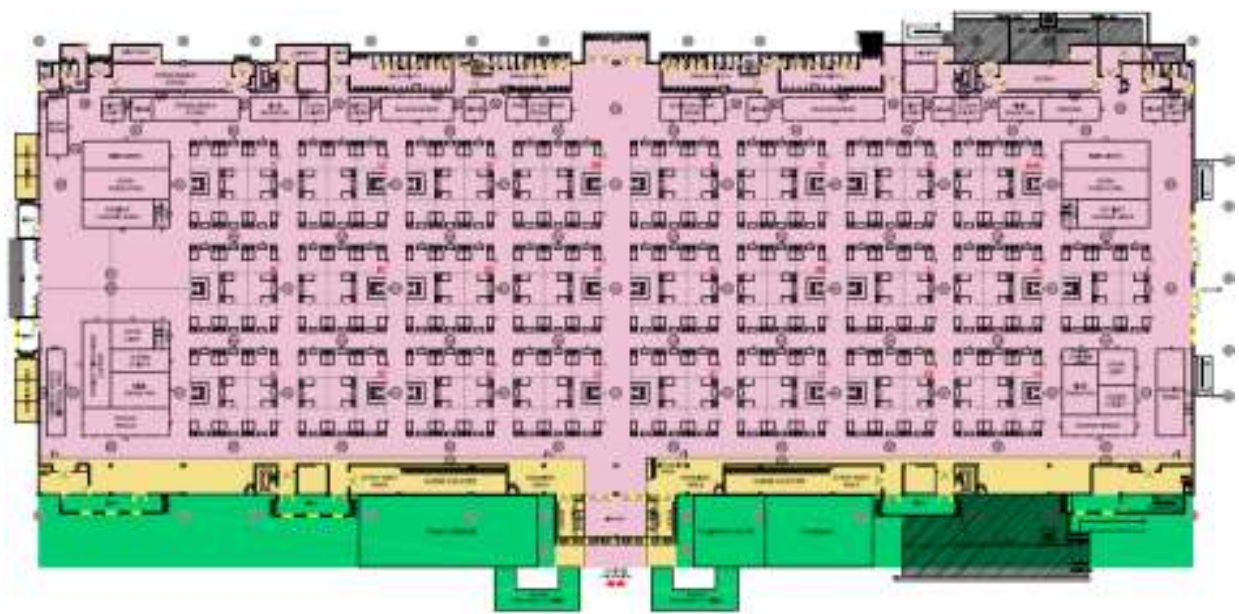

Fig. 3: The plan layout of MAEPS PKRC at Phase 1 (Source: Mardi Corp. Sdn. Bhd.) 


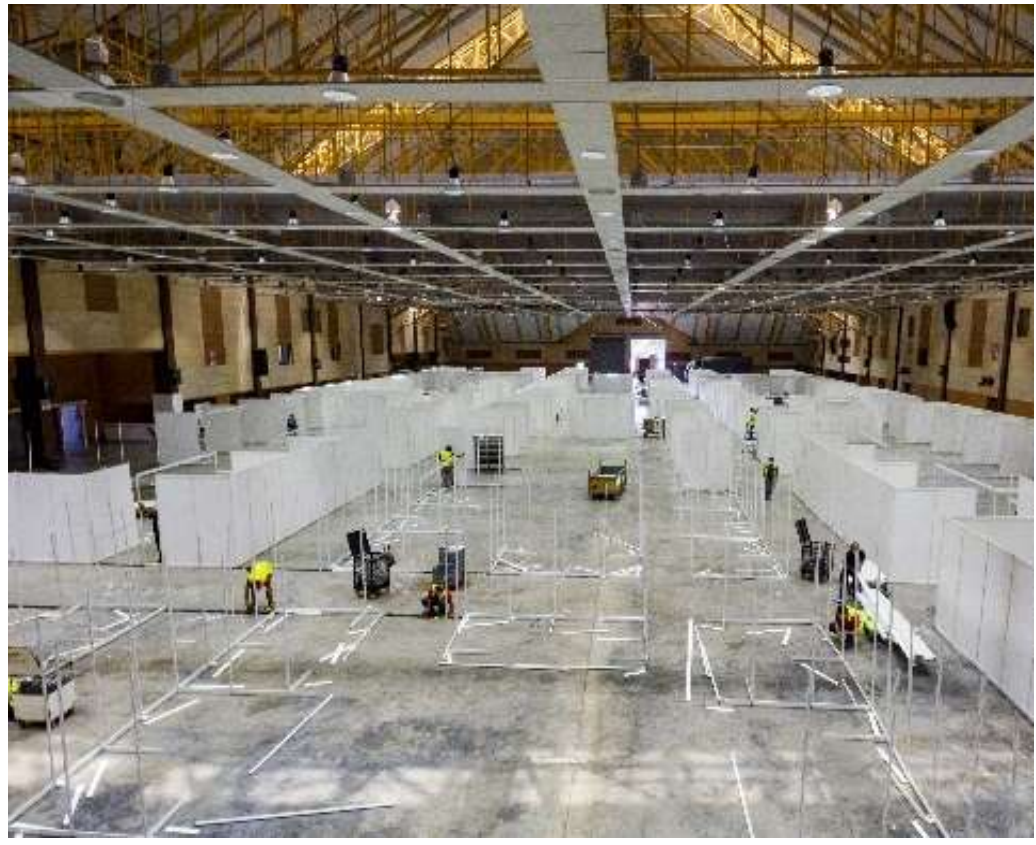

Fig. 4: The transformation work of the main hall (Source: Mardi Corp. Sdn, Bhd.)

\subsection{Discussion}

According to the specialists, the 3D visualisation of the MAEPS PKRC of Phase 1 and Phase 2 was effectively constructed. Phase 1 showed the use of compartments between zones and the arrangement of the bed. MAEPS 3D space layout creation begins with a scaled design in AutoCAD (Figure 5). The scaled design was then transformed to 3D modeling using SketchUp (Figure 6) and rendered using the V-Ray programme (Figure 7).

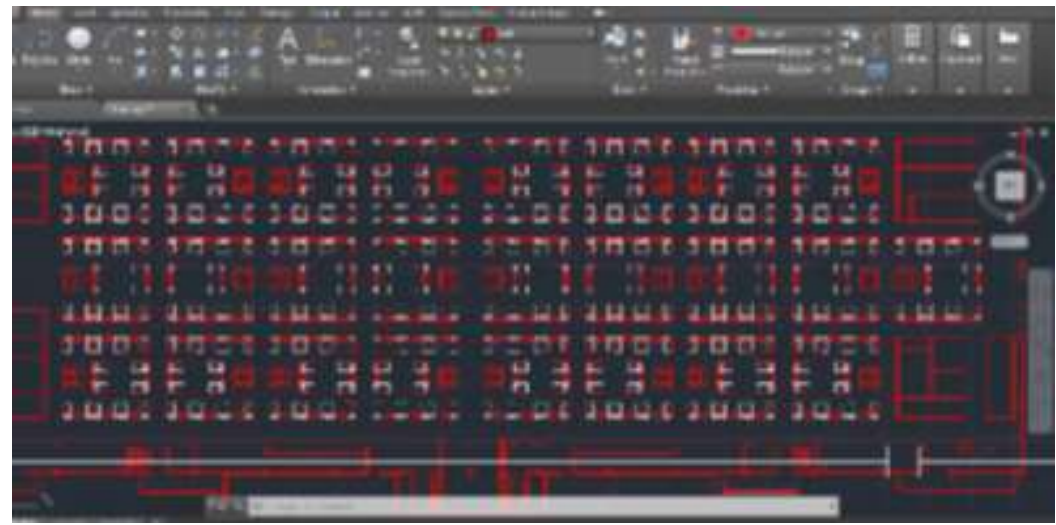

Fig. 5: The development of scaled drawing using the AutoCAD

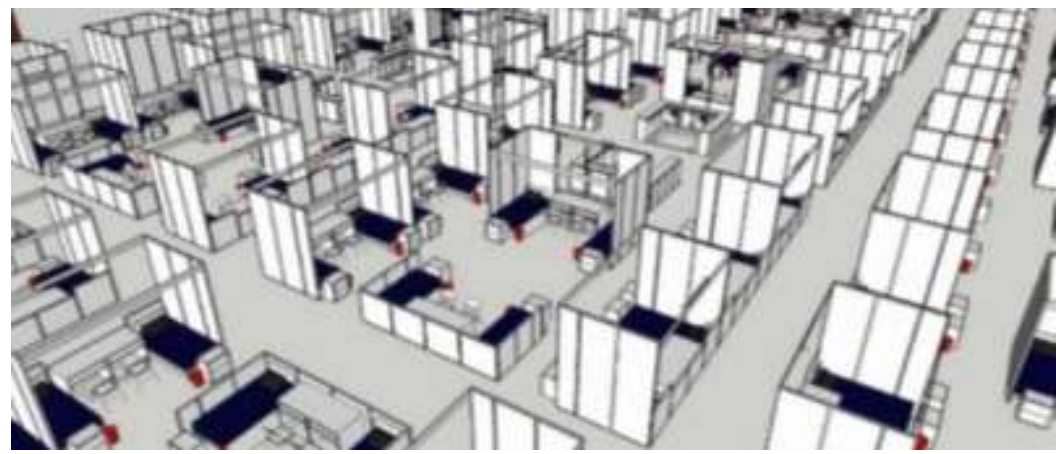

Fig. 6: The development of 3D modeling using Sketch-Up 


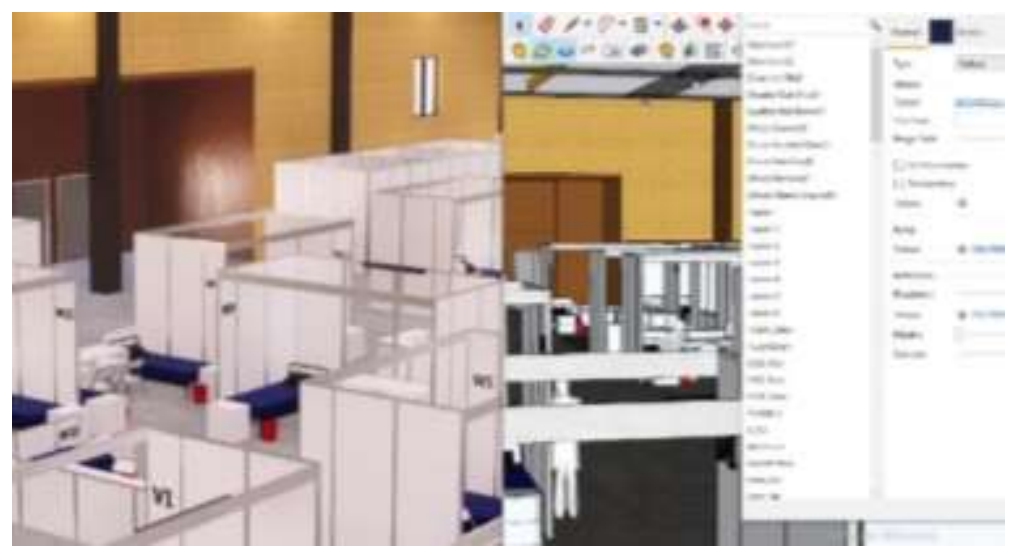

Fig. 7: The rendering process of 3D modeling using V-Ray

The 3D visualisation depicts a variety of locations and amenities that may be referred to as aesthetic guidelines and enhancements. The concepts for generating 3D visualisation can address the challenges of acceptable and appropriate bed layout, user requirements such as senior citizens and children, safety and security, and privacy. Figure 8 displays, for example, the compartment that allows the PUS to be monitored while still providing the seclusion needed for relaxation and sleep. It can also provide a thorough visual representation of the proportion of the cubicles set in the hall. Compliance with the norms, laws, and regulations pertaining to the specific application of material spaces and facilities accomplished the desired results. Figure 9 shows that the measures were in accordance with the $\mathrm{MOH}$ criteria, as the compartment panels are 3 metres tall and the space between the beds exceeds 1 metre. The 3D visualization visualizes the staff area, such as the treatment and working area, namely the Red Zone. In this Red Zone, PKRC also accommodated a lounge area for the PUS. Figure 10 shows example activities in the lounge area.

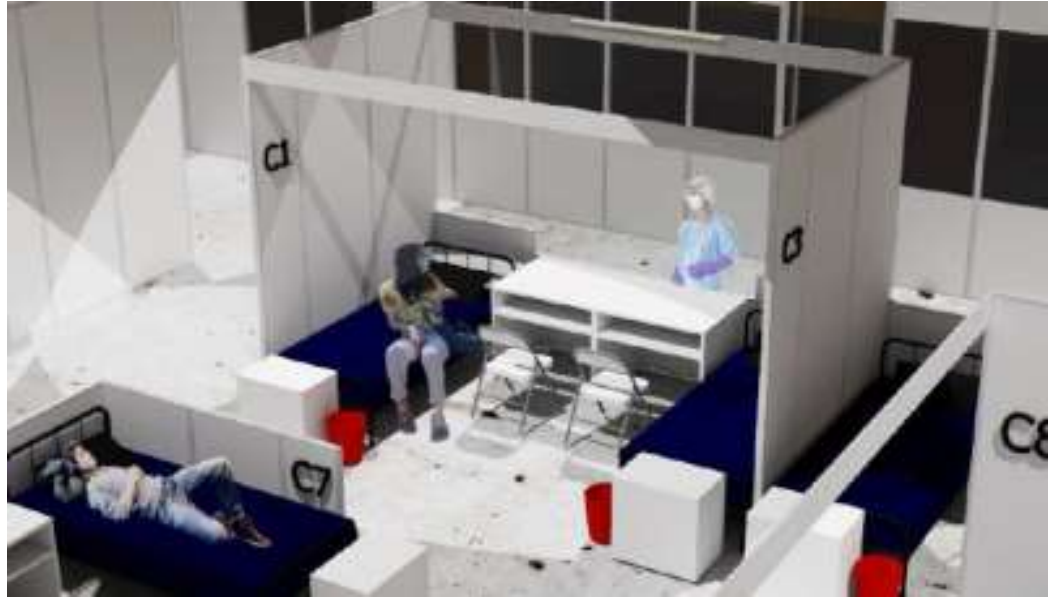

Fig. 8: The visualization of compartment installed at the hall

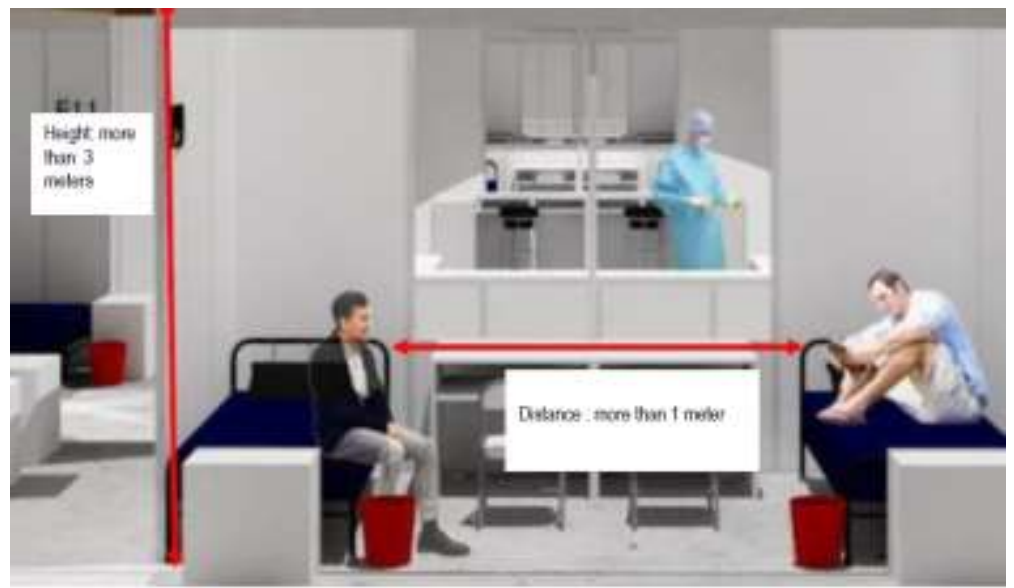

Fig. 9: The visualized measurement of the distance between the PUS 


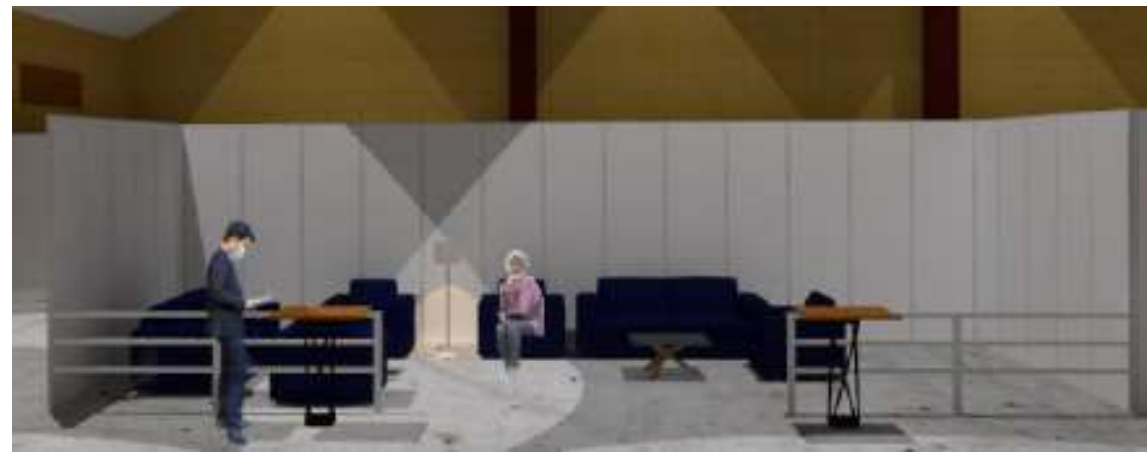

Fig. 10: The visualized example activities in the lounge area

The hall also provides the Yellow Zone dedicated to a registration counter and a surveillance area for the frontline. Figure 11 shows the compartment for the surveillance counter that complied with standard measurements to avoid direct contact with PUS.

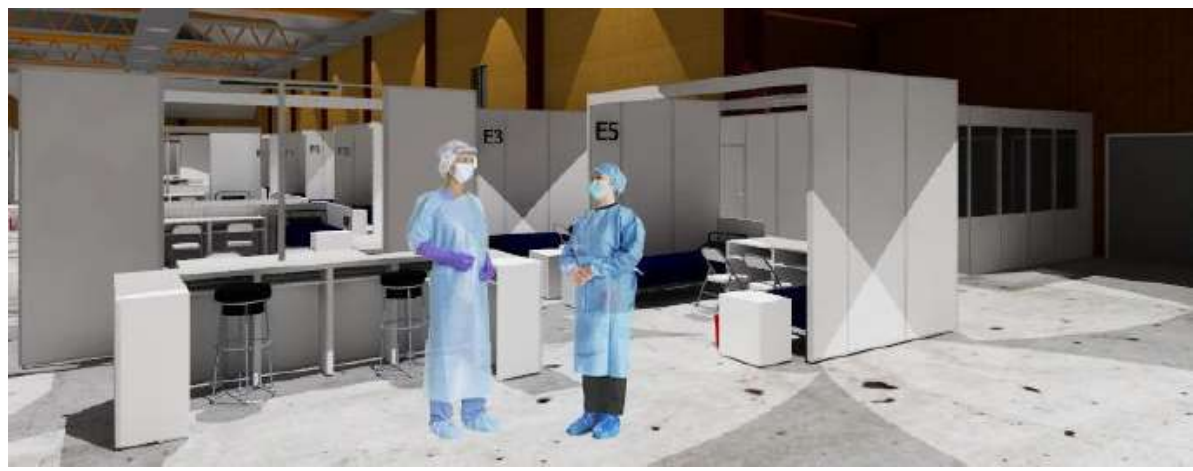

Fig. 11: The image surveillance counter in the Yellow Zone

The second phase of MAEPS PKRC significantly alters the space arrangement, particularly for positive patients in Categories 1 and 2. A better option with bunk beds was built to serve the enormous number of projected positive patients to this PKRC, which can accommodate up to 10,000 people. Figure 12 depicts the bunk bed configuration in Phase 2 of PKRC in MAEPS, where the walls were decreased and removed, as in Phase 1. Thus, the person in charge of building a new PKRC at any moment in the future can stimulate the comparative spatial arrangement of Phase 1 and Phase 2 of MAEPS PKRC.

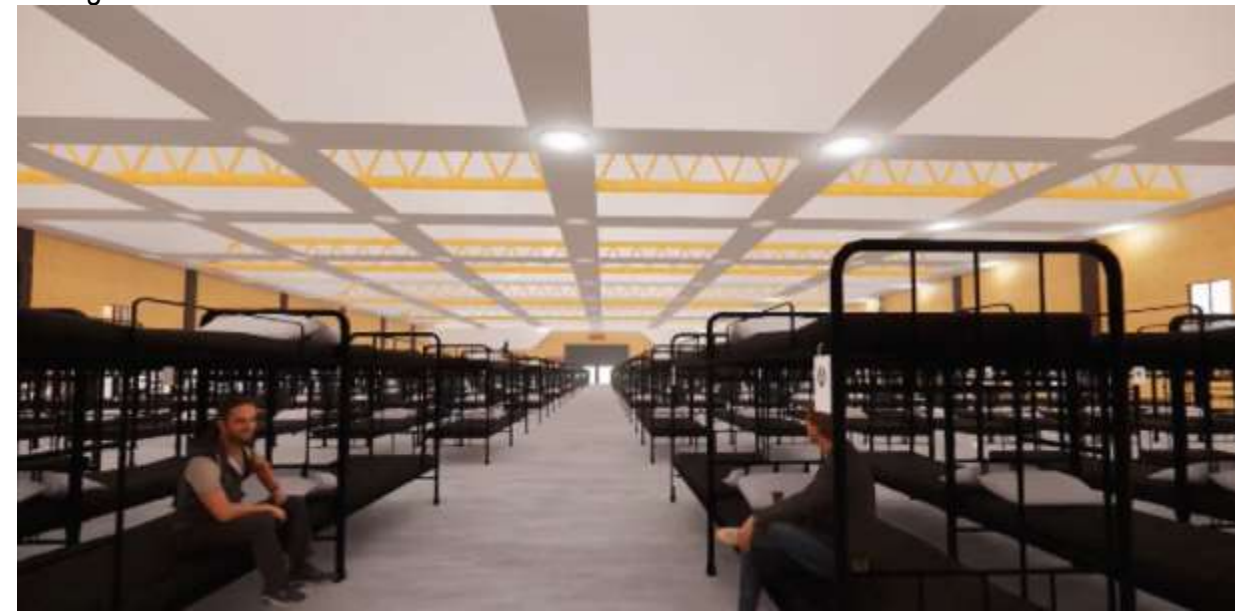

Fig. 12: The visualized of bunk beds arrangement in Phase 2

The 3D representation of both Phase 1 and Phase 2 might serve as a future reference for upgrading the facility layout at the quarantine centre. Respected organisations can improve the spatial domain of the private, semi-private, and public regions. For example, bunk bed users, particularly those on the higher level, must evaluate their age and infirmity since the older person is better suited to a single bed. As a result of the 3D visualisation, the quarantine center's bed arrangement can show the zoning area for the patients and compute the capacity of the specific hall. Controlled access via zoning can be used to designate the privacy of patients and the protection of their possessions. 


\subsection{Conclusion and Recommendations}

The 3D animation of the PKRC layout shown by MAEPS's PKRC can be utilised as a model for other states when converting a public area to a PKRC. This study is confined to the PKRC created at MAEPS and focuses solely on Hall A. The 3D visualisation may be thought of as a template for the relevant authorities to govern the region and organise the layout in order to confine the low-risk Covid-19 patients. Because our awareness of the properties of the Covid-19 virus is growing at an exponential rate, the design of the PKRC has undergone various changes, such as the use of a divider between the cubicles. As a result, there are two sorts of PKRC layouts, both of which might be valuable references in the future. Because the PKRC is only accessible to first responders and patients, this 3D visualisation also helps to disseminate information about Covid-19 quarantine and low-risk treatment centres in Malaysia to the general public. As the PKRC is a transient environment that only emerges during pandemics or emergencies, such as today, the 3D animation of the PKRC helps to teach through the explorative space layout created that may be referred to in classroom and study. The PKRC's 3D animation also highlights the historical moments of Malaysians confronted with the Covid-19 epidemic, which might be our future historical health event. This 3D visualization can be developed further to be as Augmented Reality and Virtual Reality in the future. Future researchers also recommended developing 3D visualization of the other quarantine centres and comparing it with Malaysia Agriculture Expo Park Serdang (MAEPS).

\section{Acknowledgment}

The authors would like to thank the Universiti Malaysia Kelantan's Research, Innovation and Commercialisation Centre (RMIC) for funding this study under the UMK Covid-19 Special Grant (UMK-C19SG) R/C19/A1200/00554A/003/2020/00775).

\section{Paper Contribution to Related Field of Study}

This study determined that 3D modelling visualisation of the Low-Risk COVID-19 Quarantine and Treatment Centre (PKRC) is required as a reference for future pandemic activity. The 3D graphic displays the plan layout, pathway dimensions, zone, and space requirements required to transform a building into a quarantine facility.

\section{References}

Centofanti, M., and Brusaporci, S., Architectural 3D Modeling In Historical Buildings Knowledge And Restoration Processes, Proceeding in X Forum Internazionale di Studi, Le Vie dei Mercanti, June 2012

De Oliveira M.J.F, L. Gabcan,. 3D Visual Simulation Applied To A New Thorax Disease Institute, In: 28th ORAHS., Mario Jorge Ferreira de Oliveira (Ed), Accessibility and Quality of Health Services. Peter Lang, Frankfurt, p. 195- 206, 2004.

De Oliveira, M.J.F. 3D Visual Simulation Of Hospital Admissions, In: J. Riley (editor), Planning The Future: Health, Service Quality and Emergency Accessibility, Proceedings from ORAHS 2000, Glasgow 31st, July- 4 th august. 2000. 77-96.

Ministry of Health. Covid-19 Malaysia. Retrieved August 11, 2020 from Garis Panduan Kementerian Kesihatan Malaysia: Http://Covid-19.Moh.Gov.My/Garis-Panduan/GarisPanduan-Kkm/Annex_1_Case_Definition_Covid_22032020.Pdf .2020, August 6.

Mardi Corp. Sdn. Bhd. (2020) Pusat Kuarantin \& Rawatan Covid-19 Berisiko Rendah MAEPS, Serdang (Unpublished article)

Muhammad, S. A., Hanafi, N. N. H. ., Anuar, T. F. T., \& Hequan, Z. .(2021) Application of 3D Visualization for Quarantine and Treatment Centre (PKRC) Layouts in Malaysia Agriculture Expo Park Serdang (MAEPS) Vol. 6 No. 18 (2021): December 5 ABRA International Conference on Quality of Life, AQoL2021 Langkawi Island, Malaysia, 1516 Dec 2021 https://doi.org/10.21834/ebpj.v6i18

Personal interview with Chief Executive Officer of Mardi Corp., Encik Zaidi Shahrim. Malaysia Agriculture Expo Park Serdang (MAEPS), Serdang. September 8, 2020.

Rafidah M. R. BH Online. from COVID-19: 152 diisytiharkan Stesen Kuarantin: https://www.bharian.com.my/berita/nasional/2020/04/672568/covid-19-152-diisytiharkanstesen-kuarantin $3^{\text {rd }}$ April, 2020. Retrieved August 13, 2020

Hanafi , N. N. H. ., Mohamad , J. ., Muhammad, S. A. ., \& Mhd. Zain, M. H. K. . (2021). Lessons Learned from the Adaptations of Post-Flood Housing Reconstruction in Kuala Krai, Kelantan. Environment-Behaviour Proceedings Journal, 6(17), 227-234. https://doi.org/10.21834/ebpj.v6i17.2820 